Christina E. Adamsen • Jens K. S. Møller •

Ramadan Hismani $\cdot$ Leif H. Skibsted

\title{
Thermal and photochemical degradation of myoglobin pigments in relation to colour stability of sliced dry-cured Parma ham and sliced dry-cured ham produced with nitrite salt
}

Received: 29 October 2003 / Published online: 3 March 2004

(C) Springer-Verlag 2004

\begin{abstract}
Lipophilic and hydrophilic extracts of the red pigments from Parma ham and nitrosylated pigment of dry-cured ham produced with nitrite salt were prepared with acetone/water (75/25 v/v \%) solution and aqueous phosphate buffer, respectively. The spectral characteristics differed for both the lipophilic and the hydrophilic Parma ham pigment compared with the dry-cured ham produced with nitrite salt. The red lipophilic pigment(s) extractable from Parma ham was(were) found to be very stable towards thermal degradation in acetone/water $(75 / 25 \mathrm{v} / \mathrm{v} \%)$ solution for temperatures up to $70{ }^{\circ} \mathrm{C}$ in contrast to the lipophilic pigment(s) extractable from drycured ham produced with nitrite salt, which was(were) found to have an energy of activation of $99 \mathrm{~kJ} / \mathrm{mol}$ for thermal degradation. In contrast, quantum yields for photodegradation of the lipophilic ham pigments exposed to $366 \mathrm{~nm}(420 \mathrm{~nm})$ monochromatic light were larger for Parma ham than for nitrite-cured ham $\left[1.6 \times 10^{-5}\right.$ $\left(6.9 \times 10^{-6}\right)$ versus $1.6 \times 10^{-6}\left(2 \times 10^{-6}\right)$ mol einstein $^{-1}$ ] as determined for acetone/water $(75 / 25 \mathrm{v} / \mathrm{v} \%)$ solution. In agreement with these findings for the extracted lipophilic pigments, sliced Parma ham showed better colour stability than sliced dry-cured ham produced with nitrite salt, when stored in the dark at low oxygen concentration, in contrast to a faster initial discolouration for Parma ham when exposed to light, as shown for chilled storage for 35 days under retail conditions for the two products each packed at two oxygen levels (0.4 and 21\%).
\end{abstract}

Keywords Dry-cured Parma ham · Dry-cured ham produced with nitrite salt . Colour stability .

Photodegradation - Thermal degradation

C. E. Adamsen · J. K. S. Møller · R. Hismani · L. H. Skibsted ( Food Chemistry, Department of Dairy and Food Science,

The Royal Veterinary and Agricultural University, Rolighedsvej 30, 1958 Frederiksberg C, Denmark

e-mail: 1s@kvl.dk

Tel.: +45-32283221

Fax: +45-35283344

\section{Introduction}

Colour is an important sensory property of many foods and contributes greatly to their overall acceptability. The characteristic pink colour of nitrite-cured meat products has a special role in consumer acceptance, as a stable pink colour is usually associated with high quality of such processed meat products [1]. Curing with salt added nitrite/nitrate is generally used to achieve a stable red colour of both dry-cured and brine-cured meat products. However, the unique red colour of dried cured hams from the Parma region in Italy develops from muscle myoglobin during maturation solely as a consequence of salting with sodium chloride and dehydration. Parma hams are made only from pork legs and sodium chloride in the form of sea salt from the Mediterranean Sea. The ham is renowned for its bright red colour and its characteristic flavour and texture $[2,3]$.

The pathway of formation and even the exact identity of the pigments of Parma ham still remain unknown. The pigment of Parma ham is, however, now known to be different from nitrosylmyoglobin, which is formed in nitrite-cured meat products, as has been shown by electron spin resonance spectroscopy $[4,5,6]$. Virgili et al. [7] have suggested that the low molecular weight compounds containing electron donor atoms (mainly nitrogen), which are formed during maturation of Parma ham, in particular peptides and amino acids resulting from an extensive proteolysis, may play a role as ligands in myoglobin.

Sakata et al. [4] showed that pigments extracted with water from Parma ham were stable in the $\mathrm{pH}$ region 5-10 under ambient aerobic conditions. Other studies dealing with the stability of Parma ham pigments have shown that pigments extracted with aqueous phosphate buffer from Parma ham are stable towards oxidation by ferricyanide and also rather stable towards autoxidation at ambient conditions [8]. The same study also showed that the red pigments extracted with acetone/water $(75 / 25 \mathrm{v} / \mathrm{v} \%)$ solution from Parma ham or with aqueous buffer are stable in darkness, but degraded within 3 days when kept 
under light at 4 and $20{ }^{\circ} \mathrm{C}$ [8]. Furthermore, no effect of vitamin $\mathrm{E}$ on colour intensity or stability was observed in Parma ham manufactured from pigs supplemented with vitamin $\mathrm{E}$ in comparison with pigs from a normal feeding regime [9]. In the same study the colour stability of sliced Parma ham packed in vacuum or in a protective atmosphere $\left(85 \% \mathrm{~N}_{2}\right.$ and $\left.15 \% \mathrm{CO}_{2}\right)$ exposed to fluorescent light was investigated, and it was concluded that the colour of the sliced Parma ham was maintained for about 2 months, as evaluated by sensory analysis [9].

The stable red pigment of Parma ham is also of interest from a more general meat processing point of view, since it presents future perspectives for manufacturing meat products with a desirable colour without the use of either nitrate or nitrite. Safety aspects of using especially nitrite as an additive have been discussed over the past decades.

The objective of the present study was to investigate the physicochemical properties of the Parma pigment as extracted from the ham in comparison with the pigments extracted from dry-cured ham produced with added nitrite. More specifically, the susceptibility of the pigments towards photodegradation and thermal decomposition were investigated for pigments isolated from Parma ham and from dry-cured ham produced with nitrite salt. Moreover, the light sensitivity of both of the meat products was evaluated in a chill storage experiment, where sliced Parma ham and sliced, dry-cured ham produced with nitrite salt packed in high and in low oxygen atmospheres were stored in the dark or exposed to light of 1,000 lx intensity under retail conditions.

\section{Materials and methods}

\section{Chemicals}

Acetone, sulphuric acid (95-97\%), hydrogen peroxide (30\%), sodium thiosulfate, calcium chloride dihydrate, phenantrolin, sodium acetate, nitric acid (65\%), silver nitrate, vanadium(III) chloride and sodium nitrite were all obtained from Merck (Darmstadt, Germany). Chloroform and methanol were obtained from Lab-Scan (Dublin, Ireland.). 2',7'-Dichlorofluorescein, $N$-(1-naphthyl)ethylenediamine dihydrochloride (NEDD), Griess reagent, and sulfanilamide (SULF) were purchased from Sigma-Aldrich (Steinheim, Germany). Potassium ferrioxalate was obtained from $\mathrm{K} \& \mathrm{~K}$ Laboratories, Division of Biomedicals (Cleveland, OH, USA). All chemicals were of analytical grade and were used without further purification. Water was purified through a Millipore Q-Plus unit (Millipore, Bedford, MA., USA).

\section{Meat samples}

Fully matured Parma ham (total processing time of 18 months) was obtained from a local producer in Parma through Stazione Sperimentale per I'Industria delle conserve Alimentari, Parma, Italy. The dry-cured ham made with nitrite salt (assigned standard dry-cured ham hereafter) was obtained from Tulip International (Viby J., Denmark).

\section{Packaging and storage conditions}

Sliced ham (thickness $3 \mathrm{~mm}$ ) samples were placed in $22.5 \mathrm{~cm} \times$ $15.5 \mathrm{~cm}$ bags of a laminated packaging material (polyamide/ethyl vinyl alcohol/polyamide $40 \mu \mathrm{m} /$ linear low-density polyethylene $75 \mu \mathrm{m}$, AMCOR, Unibags, Denmark) with an oxygen transmission rate of $0.45 \mathrm{~cm}^{3} \mathrm{~m}^{-2} \mathrm{~atm}^{-1} 24 \mathrm{~h}^{-1}$ (measured at $23{ }^{\circ} \mathrm{C}$ and $5 / 95 \%$ relative humidity), a carbon dioxide transmission rate of $1.8 \mathrm{~cm}^{3}$ $\mathrm{m}^{-2} \mathrm{~atm}^{-1} 24 \mathrm{~h}^{-1}$ (measured at $23{ }^{\circ} \mathrm{C}$ and $5 / 95 \%$ relative humidity) and a water-vapour transmission rate of $3.9 \mathrm{~g} \mathrm{~cm}^{-2}$ (measured at $23{ }^{\circ} \mathrm{C}$ and $50 \%$ relative humidity), which were heat-scaled. The volume ratio of headspace to meat was $12: 1$ and the oxygen concentration in headspace was $21 \%$ or $0.4 \%$. The samples were stored in the dark or exposed to light in chill cabinets (Termaks series 6000 , Termaks, Solheimsviken, Norway), and the temperature was monitored continuously during storage at two different locations in each chill cabinet using data loggers (Tinytalk II-Temp Loggers, RS Radio Parts, Copenhagen, Denmark). The mean storage temperature was $6.2{ }^{\circ} \mathrm{C}$. Fluorescent tubes (Philips New Generation TLD, 36 W/830, Copenhagen, Denmark) were used for illumination, yielding an illuminance of about 1,000 $\mathrm{lx}$ at the surface of the meat samples. The samples stored in the dark were covered with black plastic. The starge period was 35 days.

\section{Analysis for the storage experiment}

On day 0 , randomly selected samples $(n=3)$ from Parma ham and from standard dry-cured ham were analysed for:

- Total fat (as grams of fat per $100 \mathrm{~g}$ of meat) by the method of Folch et al. [10].

- $\mathrm{pH}$ as measured in a 1:1 meat/water homogenate made from $5 \mathrm{~g}$ of meat and $5 \mathrm{ml}$ water homogenized for $1 \mathrm{~min}$ at 15,000 rpm using a Ultra Turrax homogenizer (Janke \& Kunkel, Kika Labortechnik, Staufen, Germany). The $\mathrm{pH}$ was measured using a $\mathrm{pH}$ meter ( $713 \mathrm{pH}$ meter, $\Omega$ Metrohm, Herisau, Switzerland).

- Salt content (as grams of salt per $100 \mathrm{~g}$ of meat) determined as chloride using $1 \mathrm{~g}$ of homogenised meat sample accurately weighed and transferred into a $100 \mathrm{ml}$ conical flask together with $50 \mathrm{ml}$ boiling water. A $1 \mathrm{ml}$ aliquot of $2.00 \mathrm{M}$ nitric acid and five drops of $0.1 \%$ fluorescein indicator were added after boiling prior to titration with $0.10 \mathrm{M}$ silver nitrate.

- Protein content determined as grams protein per $100 \mathrm{~g}$ of meat. Lean meat was trimmed for any visible fat, chopped very fine and approximately $2 \mathrm{~g}$ was weighed accurately on non-nitrogenous paper (AGF $257212 \times 12 \mathrm{~cm}$, Frisinette, Ebeltoft). The meat sample and the paper were transferred to a Kjeldahl tube and destroyed in a Tecator 2020 digester (Foss Tecator, Höganäs, Sweden) using a standard procedure prior to distillation in a Tecator 1026 distilling unit combined with a Titralab TIM 900 titration manager and an ABU 900 autoburette (Radiometer, Copenhagen, Denmark). A reagent blank was measured to estimate the content of the nitrogen in the reagents. The factor used to convert percentage $\mathrm{N}$ to percentage crude protein was 6.25 .

- Nitrite content (ppm) determined by the Norwitz-Keliher method [11], in which the NEDD concentration was doubled as described by Binstok et al. [12].

- Nitrate content ( $\mathrm{ppm}$ ) determined by a method based on that of Miranda et al. [13] where vanadium(III) reduces nitrate to nitrite. The digestion, clarification and filtration of the meat samples were performed as described by Norwitz and Keliher [11]. The filtrate $(25 \mathrm{ml})$ was mixed with $12.5 \mathrm{ml}$ NEDD $(1 \mathrm{w} / \mathrm{v}$ in $\left.\mathrm{H}_{2} \mathrm{O}\right), 12.5 \mathrm{ml} \mathrm{SULF}(2 \% \mathrm{w} / \mathrm{v}$ in $5 \% \mathrm{HCl}), 25 \mathrm{ml}$ of a saturated solution of $\mathrm{VCl}_{3}$ in $1 \mathrm{M} \mathrm{HCl}$ and water to make $100 \mathrm{ml}$. The absorbance was measured at $542 \mathrm{~nm}$ and total nitrite content calculated using a sodium nitrite calibration curve. The nitrate content was calculated as the difference between the nitrite content before and after addition of vanadium(III). 
- Water content (as grams of water per $100 \mathrm{~g}$ of meat) measured by a moisture analyser (Sartorius MA 30, Decagon Devices, Pullman, WA, USA).

- Water activity measured using a CX-2 water activity analyser (AQUA LAB, Pullman, WA, USA).

The gas composition of the package headspace was measured using a CheckMate 9900 gas analyser (PBI Dansensor, Ringsted, Denmark) and expressed as percentage $\mathrm{O}_{2}$ and percentage $\mathrm{CO}_{2}$.

The colour of the meat surface was measured every day for the first 4 days and later in the storage periods at appropriate intervals through the package film with a Color-guide 45/0 (BYK-Gardner, Geretsried, Germany) using the $L^{*}, a^{*}, b^{*}$ coordinates (CIE L ${ }^{*}{ }^{*}{ }^{*}{ }^{*}$ colour system). A red colour was expressed as the $a^{*}$ value, which increases with redness. The measurement was repeated on five randomly selected locations on each package for five packages for each type.

Pigment extraction

Pigments from the Parma ham or from the standard dry-cured ham were extracted with acetone/water $(75 / 25 \mathrm{v} / \mathrm{v} \%)$ solution and with aqueous phosphate buffer [6]. Extracts were kept in the dark and on ice and were used for measurements within $4 \mathrm{~h}$. The concentration of the pigment extracted from Parma ham and standard dry-cured ham was calculated from spectrophotometric measurements: $\varepsilon=199,200 \mathrm{M}^{-1} \mathrm{~cm}^{-1}$ at $416 \mathrm{~nm}$ for acetone/water $(75 / 25 \mathrm{v} / \mathrm{v} \%)$ solution; $\varepsilon=152,100 \mathrm{M}^{-1} \mathrm{~cm}^{-1}$ at $424 \mathrm{~nm}$ for aqueous phosphate buffer (pH 6.00) for Parma ham [6]; $\varepsilon=146,800 \mathrm{M}^{-1} \mathrm{~cm}^{-1}$ at $421 \mathrm{~nm}$ for both acetone/water $(75 / 25 \mathrm{v} / \mathrm{v} \%)$ solution and aqueous phosphate buffer ( $\mathrm{pH}$ 6.00) for standard dry-cured ham [14].

Photodegradation of ham pigments

A continuous-wave photolysis technique was employed during which a four-window cuvette with the ham extracts was exposed for a period of $12 \mathrm{~h}$ to monochromatic light (366 and $420 \mathrm{~nm}$ ) selected by a monochromator from a Xe lamp. The light was focused by an optical system with a light condenser and shutter connected to a timer into the cuvette in the thermostated $\left(25 \pm 0.5{ }^{\circ} \mathrm{C}\right)$ cell holder with magnetic stirring in a HP 8453 UV-vis diode-array spectrophotometer (Hewlettt-Packard, Palo Alto, CA, USA), and absorption spectra (from 300 to $700 \mathrm{~nm}$ at $2 \mathrm{~nm}$ intervals) were recorded at appropriate time intervals. Light intensities at 366 and $420 \mathrm{~nm}$ were determined by ferrioxalate actinometry [15]. Quantum yields for photooxidation of ham pigments extracted with acetone/water $(75 / 25 \mathrm{v} / \mathrm{v} \%)$ solution were determined from absorption spectra recorded during photolysis and light intensities as determined by actinometry [16]. The quantum yield defined as

$\phi_{\text {irr }}=\frac{\text { moles of pigment reacted }}{\text { moles of photons absorbed by pigment }}$

was calculated from the change in concentration of the pigment as monitored spectrophotometrically. The intensity of light at the wavelength of irradiation as determined by actiniometry was corrected to the fraction of light absorbed $\left(A_{\text {irr }}\right)$ in the cuvette by the factor $1-10^{-A_{\text {irr }}}$ derived from the Lambert-Beer law.
Thermal degradation of ham pigments

Ham pigment $(100 \mathrm{ml})$ extracted with acetone/water (75/25 v/v \%) solution or aqueous phosphate buffer was kept at $30,40,50,60$ or $70{ }^{\circ} \mathrm{C}$ for $3 \mathrm{~h}$ in a thermostat. The spectra from 350 to $700 \mathrm{~nm}$ were recorded at $30 \mathrm{~min}$ intervals for $3 \mathrm{~h}$ with a Cintra $40 \mathrm{UV}-\mathrm{vis}$ spectrophotometer (VEB Analytical, GBC Scientific Equipment, Australia), except for $70{ }^{\circ} \mathrm{C}$ for which temperature spectra were measured at $15 \mathrm{~min}$ intervals. Extracts becoming turbid were centrifuged $\left(5{ }^{\circ} \mathrm{C}, 15,000 \mathrm{rpm}\right.$ for $\left.5 \mathrm{~min}\right)$ prior to the spectrophotometric measurements. The pigment concentration was followed from changes in absorbance at the Soret band [Parma ham pigment, acetone/water (75/25 v/v \%) solution $416 \mathrm{~nm}$; Parma ham pigment aqueous phosphate buffer $424 \mathrm{~nm}$; standard dry-cured ham pigment, acetone/water (75/25 v/v \%) solution $400 \mathrm{~nm}$; standard drycured ham pigment, aqueous phosphate buffer $412 \mathrm{~nm}]$. The decomposition of the extracted pigments was expressed as percent decomposed assuming that absorbance would decrease to zero for complete degradation:

Relative pigment content $(\%)=\left[1-\left(\frac{A_{t=0}-A_{t=x}}{A_{t=0}}\right)\right] \times 100 \%$.

Data analysis

Average values of fat, moisture, protein, $\mathrm{NaCl}, a_{\mathrm{w}}, \mathrm{pH}$, nitrite and nitrate contents of Parma ham and standard dry-cured hams and the quantum yield for photodegradation were compared by the Student $t$-test in the Analyst application within the SAS system statistical software release 8.02 (SAS Institute, Cary, NC, USA). The spectral changes during thermal decomposition of pigment extracted from Parma ham and standard dry-cured ham with acetone/water (75/ $25 \mathrm{v} / \mathrm{v} \%$ ) solution and aqueous phosphate buffer were analysed using a kinetic model with a single-exponential decay corresponding to a first-order reaction. The analyses were carried out using Microcal Origin version 6.0 (Microcal Software, MA, USA). The first-order rate constants were further analysed according to the Arrhenius equation in order to estimate the activation energy $\left(E_{\mathrm{a}}\right)$ for thermal decomposition of the four pigments.

\section{Results and discussion}

Parma ham produced according to the official regulation in the Parma region in Italy and a standard dry-cured ham produced by the Danish meat industry and produced with salt-added nitrite were compared with respect to colour stability and pigment properties. The compositions of the two hams used for this comparison are presented in Table 1. The hams are rather similar in composition except for the content of nitrite and nitrate, which were both below the detection limit for the Parma ham. The salt content is significant higher and the water activity correspondingly lower for the standard dry-cured ham than for Parma ham.

Table 1 Approximate composition of the Parma ham and the standard dry-cured ham. Means with the same superscript letter in the same column are not significantly different at a $5 \%$ level

\begin{tabular}{|c|c|c|c|c|c|c|c|c|}
\hline & $\begin{array}{l}\text { Fat } \\
\text { (g/100 g } \\
\text { meat) }\end{array}$ & $\begin{array}{l}\text { Moisture } \\
\text { (g/100 g } \\
\text { meat) }\end{array}$ & $\begin{array}{l}\text { Protein } \\
\text { (g/100 g } \\
\text { meat) }\end{array}$ & $\begin{array}{l}\mathrm{NaCl} \\
\text { (g/100 g } \\
\text { meat) }\end{array}$ & $a_{\mathrm{w}}$ & $\mathrm{pH}$ & $\begin{array}{l}\text { Nitrite } \\
\left.(\mathrm{ppm} \mathrm{NaNO})_{2}\right)\end{array}$ & $\begin{array}{l}\text { Nitrate } \\
\left.(\mathrm{ppm} \mathrm{NaNO})_{3}\right)\end{array}$ \\
\hline Dry-cured ham & $6.2 \pm 1.9^{\mathrm{a}}$ & $43.2 \pm 1.7^{\mathrm{a}}$ & $35.7 \pm 1.0^{\mathrm{a}}$ & $8.2 \pm 0.4^{\mathrm{a}}$ & $0.879 \pm 0.004^{\mathrm{a}}$ & $5.5 \pm 0.2^{\mathrm{a}}$ & $10.2 \pm 1.5$ & $4.8 \pm 0.4$ \\
\hline Parma ham & $6.9 \pm 0.6^{\mathrm{a}}$ & $45.8 \pm 2.1^{\mathrm{a}}$ & $34.9 \pm 2.8^{\mathrm{a}}$ & $5.7 \pm 0.2^{\mathrm{b}}$ & $0.913 \pm 0.002^{b}$ & $5.70 \pm 0.01^{\mathrm{a}}$ & $<1$ & $<1$ \\
\hline
\end{tabular}


Fig. 1a-d Redness parameter ( $a$ values) of sliced Parma ham and nitrite-based dry-cured ham during 35 days storage at $5{ }^{\circ} \mathrm{C}$. a Sliced Parma ham packed with $21 \%$ headspace oxygen and an illuminance level of $1,000 \mathrm{~lx}$ (squares) or of $0 \mathrm{~lx}$ (circles). b Sliced Parma ham packed with $0.4 \%$ headspace oxygen and an illuminance level of 1,000 lx (squares) or of 0 lx (circles). c Sliced standard dry-cured ham packed with $21 \%$ headspace oxygen and an illuminance level of 1,000 lx (diamonds) or of $01 \mathrm{~lx}$ (triangles). d Sliced nitrite-based drycured ham packed with $0.4 \%$ headspace oxygen and an illuminance of 1,000 lx (diamonds) or of $0 \mathrm{~lx}$ (triangles)
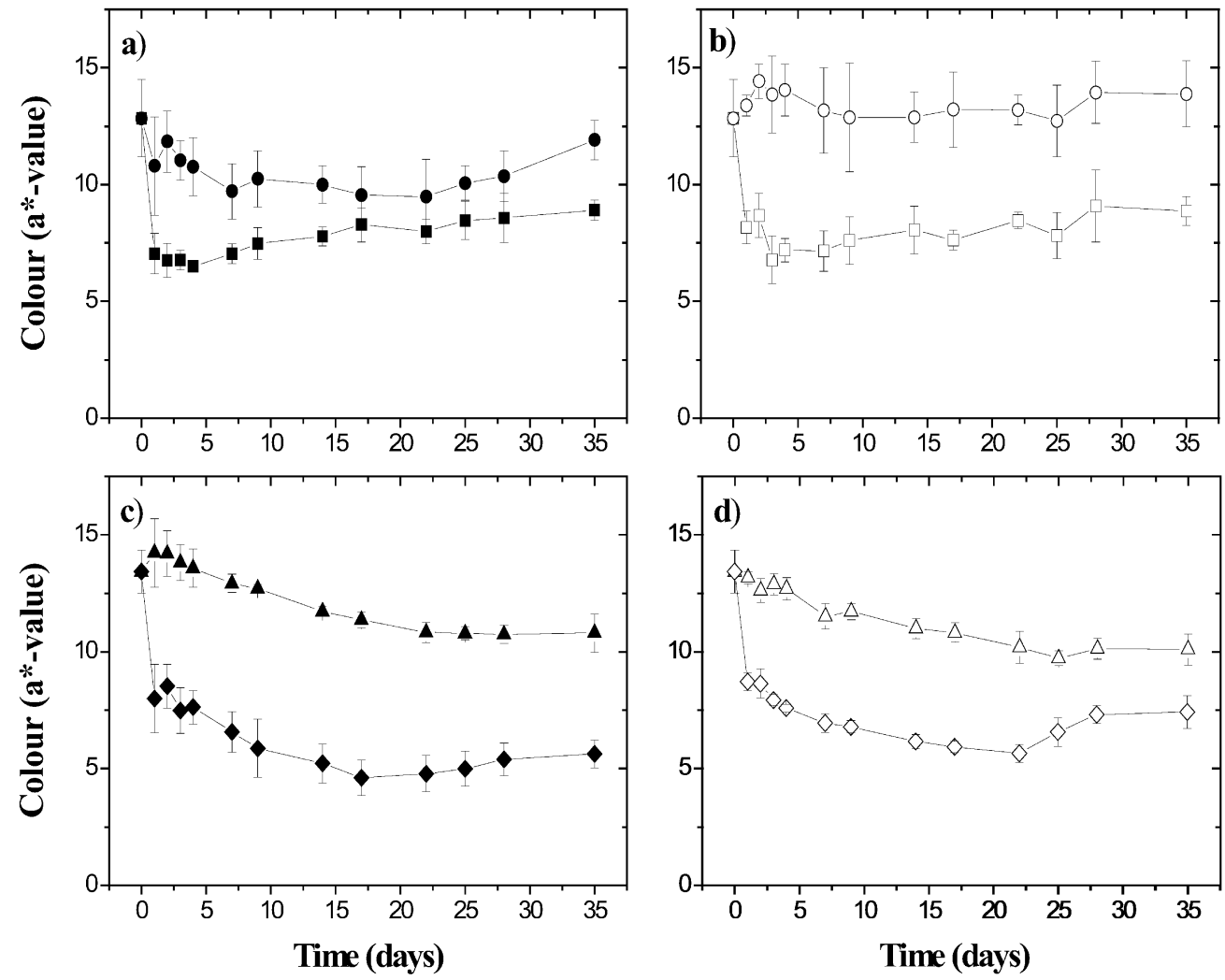

Colour stability during storage

The colour stability for sliced Parma ham and sliced standard dry-cured ham was monitored as the $a^{*}$ value through a 35 day storage period in a chill cabinet under retail display condition. The change in the $a^{*}$ value (redness) of Parma ham and standard dry-cured ham for two levels of oxygen in the headspace (21 and $0.4 \%)$ and two levels of illumination (0 and 1,000 $1 \mathrm{x}$ ) is shown in Fig. 1. The rates of discoloration for Parma ham and standard dry-cured ham exposed to light either in $21 \%$ or in $0.4 \%$ oxygen in headspaces were very similar, with both types of ham showing a significant drop in the $a^{*}$ value from day 0 to day 1 , and the rate of discoloration were surprisingly independent of the oxygen level. From Fig. 1a a slower rate of discoloration is evident for Parma ham stored in the dark in $21 \%$ oxygen and for standard dry-cured ham stored in the dark in $21 \%$ (Fig. 1c) or $0.4 \%$ (Fig. 1d) oxygen compared with the illuminated samples. However, for both types of ham stored in the dark under these conditions a significant discoloration still occurs, in contrast to what is seen for Parma ham stored in $0.4 \%$ oxygen in the dark (Fig. 1b), which maintains the red colour throughout the storage period. Illumination decreases colour stability for standard dry-cured hams and any difference between the rate of discoloration for standard dry-cured ham stored in $21 \%$ oxygen and in $0.4 \%$ oxygen was insignificant, when the product was exposed to light and also when it was kept in the dark, although a clear difference is seen between light-exposed and light-protected samples. In contrast, the colour of Parma ham was found to be stable when the product was kept in the dark in an initial atmosphere of $0.4 \%$ oxygen.

During the storage period the gas composition of the package headspace was measured. For Parma ham and standard dry-cured ham stored in an initial $21 \%$ oxygen atmosphere in the headspace, a drop in oxygen content from $21 \%$ to below $5 \%$ was observed from the start of the storage to 20 days of storage. This decrease in headspace oxygen was observed both for samples exposed to light or for samples protected against light. For Parma ham and standard dry-cured ham stored in an initial atmosphere of $0.4 \%$ oxygen, an increase in oxygen content from $0.4 \%$ to approximately $1 \%$ was seen for 7 days of storage followed by a decrease in oxygen to below $0.2 \%$. This sequence, which reflects the balance between oxygen consumption of the product and oxygen penetration though the packaging film, was observed both for samples stored exposed to light and for samples protected against light.

\section{Spectral characterisation}

The pigments in Parma ham and standard dry-cured ham were extractable with acetone/water solutions as has been shown previously [6, 17]. However, the extraction was not completed since the meat after extraction still displayed a weak pink colour. The absorption spectra in the visible region (350-650 nm) of Parma ham and 


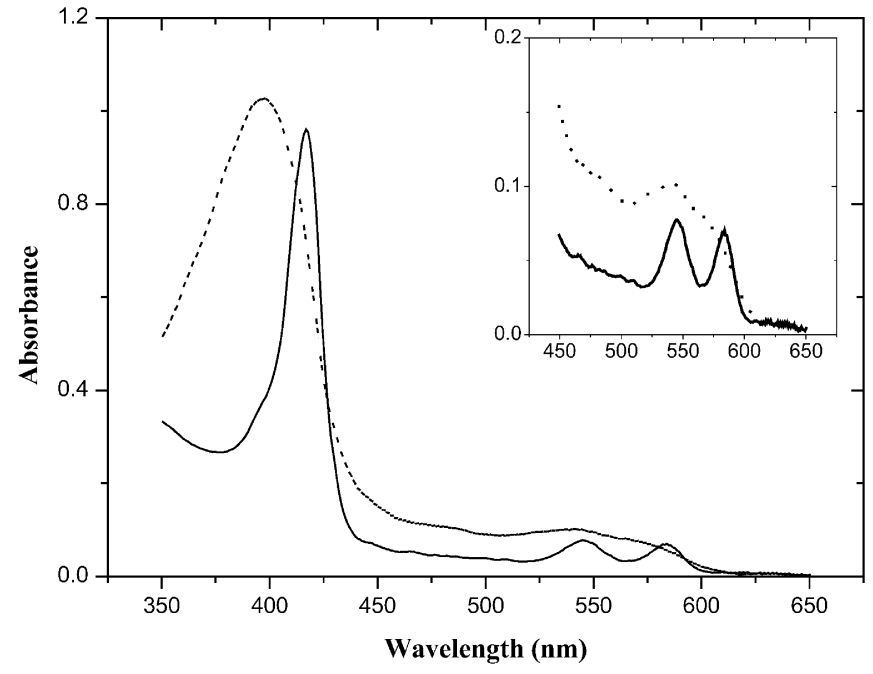

Fig. 2 Absorption spectra in the visible region of Parma ham pigment (full line) and standard dry-cured ham pigments (dotted line) extracted with acetone/water $(75 / 25 \mathrm{v} / \mathrm{v} \%)$ solution. In each case $10 \mathrm{~g}$ of ham was extracted with $90 \mathrm{~g}$ of extraction solvent. The inset shows the absorption region from 450 to $650 \mathrm{~nm}$ in detail

standard dry-cured ham pigments extracted with acetone/ water solution were clearly different (Fig. 2). The Parma ham showed maxima at 418, 546 and $582 \mathrm{~nm}$, in agreement with the findings of Møller et al. [6] and Morita et al. [17]. The standard dry-cured ham showed maxima at 396 and $540 \mathrm{~nm}$, and shoulders at 475 and $570 \mathrm{~nm}$ as is typical for nitrosylated myoglobin derivatives [18]. The pigments from Parma ham were also extractable with aqueous phosphate buffer and as for acetone/water extraction, the extracted meat had a weak pink colour. The pigments of standard dry-cured ham were poorly extracted by aqueous phosphate buffer and the extracted meat retained a pink colour. The absorption spectra $(350-650 \mathrm{~nm})$ of pigment extracted with aqueous phosphate buffer from Parma ham and standard dry-cured ham were mutually different and each was different from the spectrum for the acetone/water extract (Fig. 3). The aqueous extract of Parma ham showed maxima at 424, 550 and $586 \mathrm{~nm}$, all redshifted relative to the acetone/ water extract, while the standard dry-cured ham showed one clear maximum in the Soret band at $396 \mathrm{~nm}$.

Table 2 Quantum yields $(\phi)$ for photodegradation of pigments extracted from Parma ham and standard dry-cured ham for exposure to monochromatic light at $25{ }^{\circ} \mathrm{C}(420$ and $366 \mathrm{~nm})$. Pigments were extracted with acetone/water (75/25 v/v \%) solution,

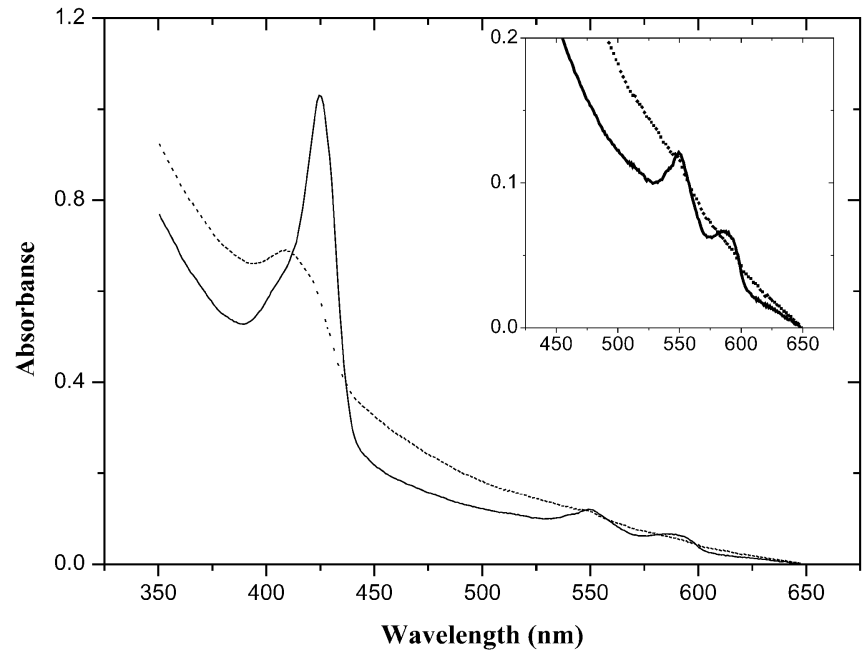

Fig. 3 Absorption spectra in the visible region of Parma ham pigment (full line) and standard dry-cured ham pigment (dotted line) extracted with aqueous phosphate buffer. In each case $10 \mathrm{~g}$ of ham was extracted with $90 \mathrm{~g}$ of extraction solvent. The inset shows the absorption region from 450 to $650 \mathrm{~nm}$ in detail

\section{Photodegradation}

The quantum yield for photodegradation of the pigments extracted with acetone/water solution was determined at $25{ }^{\circ} \mathrm{C}$, at which temperature thermal degradation is minimal (see later). The quantum yield for photodegradation provides an objective measure of the light sensitivity of Parma ham pigment and pigment from standard dry-cured ham at irradiation wavelengths of 366 and $420 \mathrm{~nm}$, which were selected as characteristic for fluorescent light $(366 \mathrm{~nm})$ and for an intense absorption for the pigment $(420 \mathrm{~nm})$, respectively. From Table 2, it is seen that the quantum yield for photodegradation was found to depend both on the pigment type and on the wavelength of irradiation. The pigment extracted by acetone/water solution from Parma ham is more sensitive to light than the pigment extracted from standard drycured ham. The quantum yield for photodegradation of standard dry-cured ham pigments exhibits at most a moderate dependence on the wavelength, in contrast to the Parma ham pigments, which are more labile for illumination at the lower wavelengths of irradiation (366 $\mathrm{nm})$.

see Fig. 2. Means with the same superscript letter in the same column are not significantly different at a 5\% level. Means with the same underlined italized letter in the same row are not significantly different at a $5 \%$ level

\begin{tabular}{lll}
\hline & Irradiation at $420 \mathrm{~nm}$ & \multicolumn{1}{c}{ Irradiation at $366 \mathrm{~nm}$} \\
\cline { 2 - 3 } & $\phi_{420}\left(\mathrm{~mol} \mathrm{einstein}^{-1}\right)$ & $\phi_{366}\left(\mathrm{~mol} \mathrm{einstein}^{-1}\right)$ \\
\hline Parma ham pigment & $6.9 \pm 2.8 \times 10^{-6}(n=3)^{\mathrm{a}, \underline{\underline{a}}}$ & $1.6 \pm 0.2 \times 10^{-5}(n=2)^{\mathrm{a}, \underline{b}}$ \\
Standard dry-cured ham pigment & $2.0 \pm 1.1 \times 10^{-6}(n=2)^{\mathrm{b}, \underline{a}}$ & $1.6 \pm 0.1 \times 10^{-6}(n=2)^{\mathrm{b}, \underline{a}}$ \\
\hline
\end{tabular}



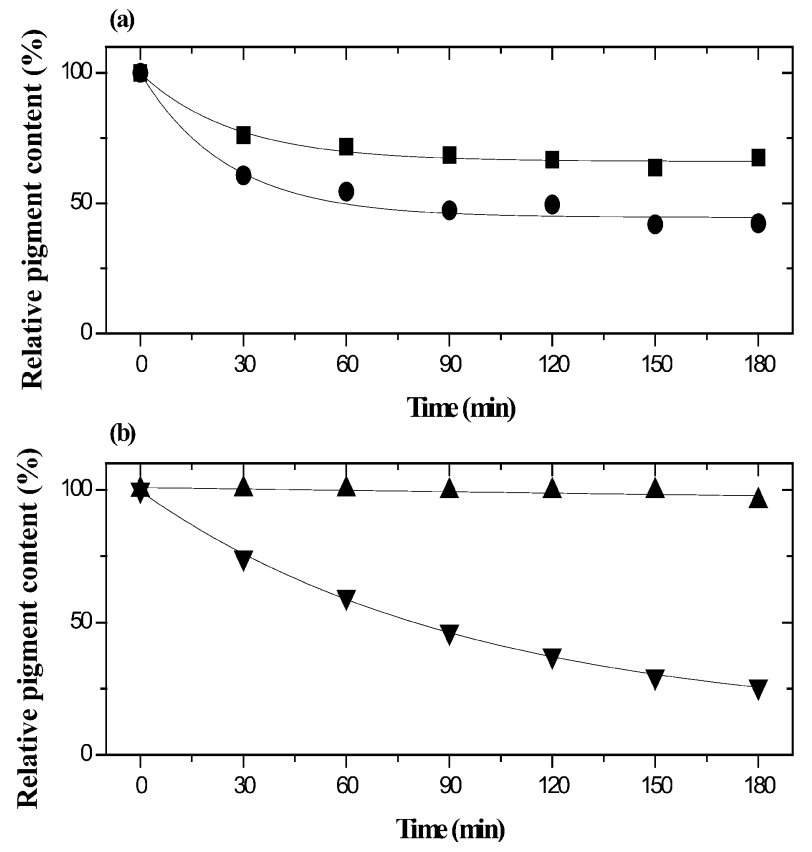

Fig. 4 Thermal degradation at $60{ }^{\circ} \mathrm{C}$ of pigments extracted from a Parma ham (squares) and standard dry-cured ham extracted with aqueous phosphate buffer (circles) and of b Parma ham (up triangles) and standard dry-cured ham extracted with acetone/water $(75 / 25 \mathrm{v} / \mathrm{v} \%)$ solution (down triangles) followed spectrophotometrically at the absorption maximum in the Soret band and expressed in relative concentration. The decrease in pigment concentration were analysed using a kinetic model with a singleexponential decay corresponding to a first-order reaction (full lines)

\section{Thermal degradation}

The thermal degradation of pigments extracted from Parma ham and standard dry-cured ham with acetone/ water solution and aqueous phosphate buffer was investigated at 30, 40, 50, 60 and $70{ }^{\circ} \mathrm{C}$. For Parma ham pigment extracted with acetone/water solution, no thermal degradation was observed in the temperature interval investigated. Thermal degradation was observed for the three other types of pigments, and the rate increased with increasing temperature. The relative pigment concentration is shown in Fig. 4 as function of time for pigments extracted with acetone/water solution and for aqueous phosphate buffer at $60{ }^{\circ} \mathrm{C}$ for both types of ham. The spectral changes during thermal decomposition of the pigments were analysed using a kinetic model with a single-exponential decay,

Relative concentration $=100 \times \mathrm{e}^{-k_{\text {obs }} t}$

corresponding to a first-order reaction as shown in Fig. 4. An adequate description of the degradation of the pigments seems to be obtained by first-order kinetics, as seen most clearly for the standard dry-cured ham pigment extracted with acetone/water solution (Fig. 4b). The temperature dependency of the observed first-order rate constant was analysed according to the Arrhenius equation for the pigment extracted from standard dry-cured
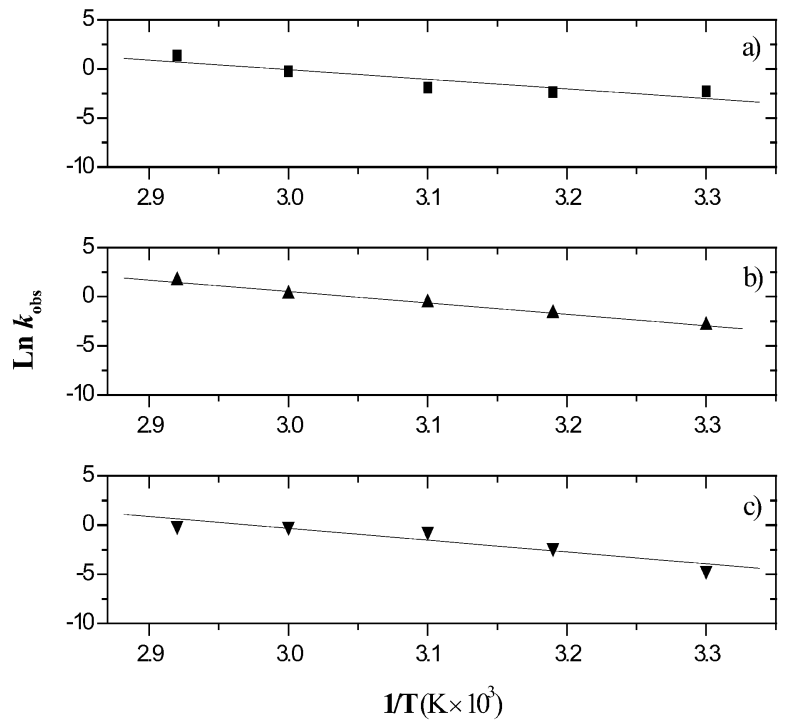

Fig. 5a-c The natural logarithms of the initial first-order rate constants (ln $k_{\text {obs }}$ ) as a function of the reciprocal absolute temperature $\left(T^{-1} \times 10^{3}\right)$. The plots are Arrhenius linearised equation fits and the slop is $-E_{\mathrm{a}} / R$. a Parma ham extracted with aqueous phosphate buffer (squares), b standard dry-cured ham pigment extracted with aqueous phosphate buffer (up triangles), and c standard dry-cured ham extracted with acetone/water (75/25 v/v \%) solution (down triangles)

ham with acetone/water solution and with aqueous phosphate buffer and for Parma ham extracts made with aqueous phosphate buffer, see Fig. 5. Activation energies were estimated and $E_{\mathrm{a}}$ had the value $81 \mathrm{~kJ} \mathrm{~mol}^{-1}$ for the Parma pigment extracted with aqueous phosphate buffer, while it was 99 and $96 \mathrm{~kJ} \mathrm{~mol}^{-1}$ for the pigment extracted from standard dry-cured ham with acetone/water solution and aqueous phosphate buffer, respectively. Notably, the lipophilic Parma ham pigment did not degrade even at $70{ }^{\circ} \mathrm{C}$.

The physicochemical properties of Parma ham extracts prepared with acetone/water solution and aqueous phosphate buffer differed for those of standard dry-cured ham both in extractability and in spectral characteristics; however, the spectral characteristics were all in agreement with some form of a modified myoglobin with an intense Soret band around $400 \mathrm{~nm}$. It is known that the maturation process of Parma ham increases the fraction of a lipophilic myoglobin derivative corresponding to the pigment(s) extracted by acetone/water solution [6]. This pigment, which dominates in the fully matured Parma ham, is the most stable towards thermal degradation, when the four different pigments are compared, in agreement with the high colour stability of unsliced Parma ham (Fig. 4).

No difference in colour stability could be observed for Parma ham and standard dry-cured ham stored in $21 \%$ or $0.4 \%$ oxygen in the package headspace, when samples were exposed to light. This part of the investigation further showed that the colour fades when sliced Parma ham is illuminated in retail packages containing even low 
headspace oxygen $(0.4 \%)$. In order to preserve the colour of Parma ham from a practical point of view, it is accordingly necessary to reduce residual oxygen in the headspace of packages, use packaging material with a high oxygen barrier, and apply a package lid that blocks light.

From the values of the quantum yield determined for photodegradation of the lipophilic Parma ham pigment and the pigment from standard dry-cured ham, it can be concluded that Parma ham pigment is more light-sensitive than standard dry-cured ham pigment extracted with acetone/water solution for illumination at both 366 and $420 \mathrm{~nm}$. However, the quantum yields were found to be rather small, and the differences seen are not reflected in a real difference in the colour stability of Parma ham and standard dry-cured ham exposed to light under retail condition (Fig. 1). However, it is clear from the storage experiment with the two types of hams, that Parma ham shows a faster initial discolouration, in agreement with the larger quantum yields, but the total discolouration is less significant especially for high oxygen storage. The quantum yields for nitrosylmyoglobin as determined in model systems show the same moderate wavelength dependency as found especially for the pigment isolated from the nitrite-cured ham $[16,19]$.

The thermal degradation of isolated pigment clearly demonstrated that the pigments are sensitive to heat. The energies of activation are relatively high as was also found for nitrosylmyoglobin in aqueous solution [16]. It is notable that these high energies of activation for degradation of the pigments are in agreement with the high colour stability seen for dark storages of especially Parma ham (Fig. 1). The lipophilic Parma ham pigment showed no sign of degradation in the temperature interval 30$70{ }^{\circ} \mathrm{C}$

In summary, the experiments clearly demonstrate that Parma ham pigments differ from the nitrosylated pigments in standard dry-cured ham produced with nitrite salt, with respect to a number of properties. Most interestingly, the lipophilic Parma ham pigment extracted with acetone/water solution exhibits superior stability towards thermal degradation and can be considered to be stable even at room temperature as long as light is excluded.

A more detailed understanding of the chemical processes behind degradation of the Parma ham pigments will, however, have to await results from our current work, which is concentrated on identifying the exact chemical structure of the Parma ham pigment(s). However, it seems evident, that the chemical properties of the lipophilic pigments of the two types of ham predict better the colour stability of the actual sliced product than pigments extracted with aqueous buffer.

Acknowledgements The present study was partly funded by the Basis Research Funding Programme of the Danish Bacon and Meat Council. Furthermore, we would like to thank Dr. Giovanni Parolari, Stazione Sperimentale per l'Industria delle Conserve Alimentari, Parma, Italy, for the kind donation of Parma ham samples and Dr. Bent Olesen, Tulip, Vejle, Denmark, for the kind donation of standard dry-cured ham samples produced with nitrite salt.

\section{References}

1. Fox JB Jr (1966) J Agric Food Chem 14:207-210

2. Parolari G (1996) Food Sci Technol Int 2:69-78

3. Sakata R (2000) Anim Sci J 71:1-16

4. Sakata R, Niu J, Morita H, Nagata Y (1998) In: Diestre A, Monfort JM (eds) Congress proceedings, meat consumption and culture. 44th international congress of meat science and technology, 30 August-4 September 1998, Barcelona, Spain. Estrategias Alimentarias, Madrid, Spain, pp 988-989

5. Morita H, Niu J, Sakata R, Nagata Y (1996) J Food Sci 61:1021-1023

6. Møller JKS, Adamsen CE, Skibsted LH (2003) Eur Food Res Technol 216:290-296

7. Virgili R, Parolari G, Bordini CS, Schivazappa C, Cornet M, Monin G (1999) J Muscle Foods 10:119-130

8. Sakata R, Morita H, Norimatsu T, Niu J (1999) Jpn J Swine Sci 36:124-129

9. Zanardi E, Novelli E, Ghiretti GP, Dorigoni V, Chizzolini R (1999) Food Chem 67:163-171

10. Folch J, Lees M, Stanley GHS (1957) J Biol Chem 226:497509

11. Norwitz G, Keliher PN (1987) Analyst 112:903-907

12. Binstok G, Campos CA, Gerschenson LN (1996) Meat Sci 42:401-405

13. Miranda KM, Espey MG, Wink DA (2001) Nitric Oxide Biol Chem 5:62-71

14. Millar SJ, Moss BW, Stevenson MH (1996) Meat Sci 42:277288

15. Hatchard CG, Parker CA (1956) Proc R Soc Lond Ser A 235:518-536

16. Andersen HJ, Skibsted LH (1992) J Agric Food Chem 40:1741-1750

17. Morita H, Sakata R, Sonoki S, Nagata Y (1994) Anim Sci Technol 65:1026-1033

18. Hornsey HC (1956) J Sci Food Agric 7:534-540

19. Møller JKS, Bertelsen G, Skibsted LH (2002) Meat Sci 60:421425 